Rocket launchers

\section{Japan enters the space race}

AfTER the successful launch of the H-I rocket last week, Japan's rocket experts are bursting with confidence. For now nothing seems to stand in the way of Japan entering the commercial satellite launching business in the 1990's nothing, except perhaps a small group of tuna fishermen.

The two-stage $\mathrm{H}$-I rocket blasted off from the National Space Development Agency (NASDA)'s space centre on Tanegashima island southwest of Kyushu at 5.45 am on 13 August. About 4 minutes later, the domestically-built cryogenic second-stage engine burst into life boosting the launcher into an eliptical orbit $1.500 \mathrm{~km}$ above the Pacific. Coasting over South America about 50 minutes later, the second-stage reignited for a brief 20 -second burn that transfered the launcher to a circular orbit before release of first the Experimental Geodetic Satellite, later named "Ajisai" (Hydrangea), and then the Japan Amateur Satellite-1, christened "Fuji" (Wisteria).

News that radiowaves from Fuji had been received in Chile was greeted with shouts of "banzai" at the headquarters of the Japan Amateur Radio League whose members have invested 5 years and 120 million yen $(£(0.5$ million) in building Japan's first ham radio satellite. It is only to be hoped that Japan's 720,000 ham enthusiasts do not overtax the little $50 \mathrm{~kg}$ satellite. Takeshi Saito, the league's amateur satellite committee chairman remembers with embarassment an incident three years ago when Japanese hams jammed the frequency band for communication with the US space shuttle Columbia and then vented their frustration by trading abuses such as "bakayaro!" - meaning "you idiot".

Equipped with 10 channels for analog communications and four for digital, Fuji comes over the Japanese archipelago six times a day permitting communications for about 10 minutes each time. A digital relay allows storage of messages which can be retransmitted on the other side of the Earth.

Ajisai, a 2-m diameter mirror ball to be used for triangulation surveys was also successfully put into orbit alongside Fuji. But the real hero of the day was the H-I rocket itself.

The LE5 second-stage cryogenic engine developed by NASDA at a cost of 44 billion yen ( $£ 192$ million) performed flawlessly, as did the Japanese-built inertial guidance system. And in a spectacular finale five hours in to orbit, the LE5 released a burst of liquid hydrogen fuel over the eastern United States, prompting reports of UFOs and exploding satellites. This is the first time the US has found itself downrange of a nation with cryogenic launchers, and may be an omen of things to come.

Japan can now forge ahead with development of the bigger $\mathrm{H}$-II which is scheduled for completion in 1991 and will be entirely made in Japan. The stage will then be set for Japan to enter the commercial market for satellite launchers. But will NASDA be able to increase launch frequency at its Tanegashima

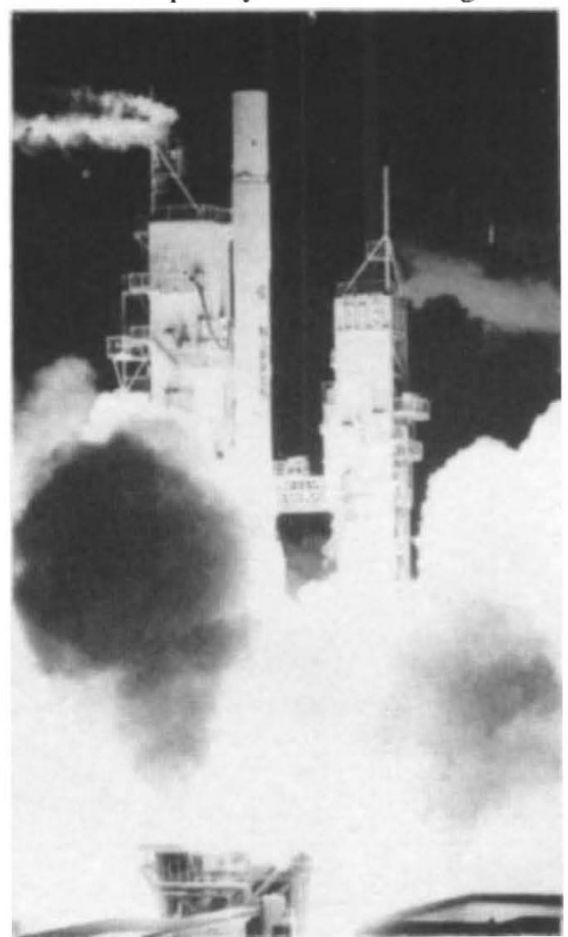

Last week s launch utllizea a US first stage but a Japanese cryogenic second stage.

Space Centre to meet the demands of foreign users?

The waters off Tanegashima teem with tuna, and under an agreement with the local fishing cooperative NASDA can only launch rockets during 90 days of the year, 45 days in summer and 45 in winter. This effectively limits NASDA to two launches a year, and for "compensation" NASDA annually pays the fishermen 600 million yen ( $£ 2.6$ million). This is over and above the 1,300 million yen reputedly paid to the fishermen when the launch site was first built.

The only inconvenience to fishermen is that during the launch a $300 \mathrm{~km}$ area of ocean extending about $30 \mathrm{~km}$ downrange of the launch site is closed to shipping. But fishing cooperatives in Japan, like other rural groups loyal to the ruling Liberal Democratic Party, have considerable political power. And if NASDA wishes to increase launch frequency in the 1990s, the local fishermen will have the final say.

David Swinbanks
US space policy

\section{No business for new shuttle}

\section{Washington}

PRESIDENT Reagan last week ended months of uncertainty over the future of the US space programme by telling the National Aeronautics and Space Administration (NASA) to build another space shuttle orbiter to replace Challenger, thus restoring the size of the shuttle fleet to four. Reagan also signalled a major policy turnaround by saying that NASA would not in future be allowed to compete with the private sector to launch commercial satellites on the shuttle, but would instead concentrate on military and research payloads. The announcement marks the end of the policy of trying to make the shuttle commercially viable.

Senior administration officials have for some months been divided over how a replacement shuttle would be paid for, and last week's announcement from the White House did little to clarify where the required $\$ 2,800$ million will be found. The White House plans to ask Congress for $\$ 2,350$ million in extra budget authority for NASA over the next 5 years, using in part "unspent funds" from other government agencies. But it is unclear to what extent NASA's other programmes will be affected. Some additional belt-tightening at the agency seems a possibility, although Reagan renewed his commitment to build a space station.

The replacement shuttle will incorporate several improvements to the existing models. New brakes, engines and computer systems were mentioned, as well as other possible safety improvements recommended by the Rogers commission into the Challenger accident. The new orbiter is not expected to be completed until 1991.

Of the 44 commercial satellites NASA is already contracted to launch aboard the shuttle, only 16 will be launched by NASA before 1992. The remainder may be shifted back to commercial unmanned launch vehicles. But because it has been US policy to rely on the space shuttle as the nation's main launch system, US aerospace manufacturers have been unwilling to get into the private launching business, and even if there is now a scramble to manufacture new commercial launchers - which some doubt - many of the payloads that might have flown on the shuttle seem destined to be launched by foreign commercial services. Besides the French Ariane rockets, which are booked up for the next several years, both China and Japan have embryonic launching services that may take a significant proportion of the backlog of satellites now waiting to be launched.
Tim Beardsley 